\title{
Risk of subsequent prostate cancer in peptic ulcer patients who received helicobacter pylori eradication therapy: an Asian population-based cohort study
}

\author{
Chu-Wen Fang ${ }^{1 \dagger}$, Chun-Hao Chen ${ }^{1 \dagger}$, Chih-Hsin Muo ${ }^{2}$ and Shih-Chi Wu ${ }^{3,4^{*}}$ (D)
}

\begin{abstract}
Background: Studies have shown diverse results regarding the association between H. pylori (HP) infection and the risk of malignancy. There is accumulating evidence relating HP infection to urological diseases. We investigated whether there was an association between HP-infected peptic ulcers and the subsequent risk of prostate cancer.

Methods: We collected HP-infected male patients from 1998 to 2008 from the Longitudinal Health Insurance Database (LHID). HP-infected patients were identified as those who had a diagnosis of peptic ulcers upon admission and received HP eradication therapy within 1 year after diagnosis. The date of HP infection diagnosis upon admission was defined as the index date. Patients aged $<20$ years or with a cancer history were excluded. For each HP-infected patient, we selected four males without peptic ulcers or a history of HP eradication in the LHID for the comparison cohort according to propensity score matching by age, index year, and comorbidity. The risk of prostate cancer and associated risk factors was assessed by Cox proportional hazard regression.

Results: A total of $2620 \mathrm{HP}$ infection treatment patients and 10,480 matched comparisons were selected. There were 36 patients in the HP-infected treatment cohort and 117 patients in the comparison cohort with documented prostate cancer development (1.52 and 1.21 per 1000 person-years, respectively). Compared to the comparison cohort, the HP infection cohort had a 1.26-fold increased prostate cancer risk in the Cox models after adjusting for matched-pairs $(95 \% \mathrm{Cl}=0.87-1.34)$. There were no significant differences in subsequent prostate cancer development between HP-infected treatment patients and the comparison cohort.

Conclusion: Our findings showed no significant association between HP-infected peptic ulcers and the subsequent risk of prostate cancer. Further studies are warranted to investigate whether this observation is attributable to an HP eradication policy.
\end{abstract}

Keywords: H. pylori, Prostatic cancer, Peptic ulcer, Cohort study

\footnotetext{
* Correspondence: rw114@mail.cmuh.org.tw

${ }^{\dagger}$ Chu-Wen Fang and Chun-Hao Chen contributed equally to this work.

${ }^{3}$ School of medicine, China Medical University, Taichung, Taiwan

${ }^{4}$ Trauma and Emergency Center, China Medical University Hospital, No. 2,

Yuh-Der Road, Taichung 404, Taiwan

Full list of author information is available at the end of the article
}

C C The Author(s). 2020 Open Access This article is licensed under a Creative Commons Attribution 4.0 International License, which permits use, sharing, adaptation, distribution and reproduction in any medium or format, as long as you give appropriate credit to the original author(s) and the source, provide a link to the Creative Commons licence, and indicate if changes were made. The images or other third party material in this article are included in the article's Creative Commons licence, unless indicated otherwise in a credit line to the material. If material is not included in the article's Creative Commons licence and your intended use is not permitted by statutory regulation or exceeds the permitted use, you will need to obtain permission directly from the copyright holder. To view a copy of this licence, visit http://creativecommons.org/licenses/by/4.0/. The Creative Commons Public Domain Dedication waiver (http://creativecommons.org/publicdomain/zero/1.0/) applies to the data made available in this article, unless otherwise stated in a credit line to the data. 


\section{Background}

There is a close association between Helicobacter pylori (HP) infection and peptic ulcer disease [1]. HP infection can often be found in most peptic ulcer patients, and eradication of HP has been associated with good outcomes [2]. Thus, medical management has now become the primary choice for the treatment of peptic ulcers [3].

Epidemiologic studies have shown that HP-infected individuals have an increased risk of gastric adenocarcinoma [4, 5] and pancreatic cancer [6], as well as a possible increased risk of colorectal adenocarcinoma [7, 8]. In contrast, studies have shown that HP infection is associated with decreased risks of esophageal adenocarcinoma and esophageal squamous cell carcinoma in Eastern populations. The possible explanation for this association might be attributed to nutritional intake, lifestyle, genetics, tumor biological characteristics and environmental factors $[9,10]$. Additionally, an inverse relationship has been shown between HP infection and gastric cardia cancer $[11,12]$. These results indicate that HP infection might play different roles in the development of various malignancies.

There is interest in the association between gastrointestinal HP infection and urological diseases, such as benign prostate hyperplasia $(\mathrm{BPH})$ and prostate cancer [13]. One study showed that HP infection should be considered in $\mathrm{BPH}$ patients because HP induces apoptosis and demonstrates extragastric effects via the atherosclerotic pathway [14]. A recent study exhibited molecular evidence of the presence of $H$. pylori DNA in prostatic tissue of patients with $\mathrm{BPH}$ and prostate cancer [15]. These studies showed that there might be an association between HP infection and urological disease.

We were interested in whether there was an association between gastrointestinal HP infection and urological prostate cancer. Therefore, we performed this population cohort study to evaluate the subsequent risk of prostate cancer in $\mathrm{HP}$-infected peptic ulcer patients.

\section{Methods}

\section{Study subjects}

We collected male patients who received HP infection treatment upon admission from 1998 to 2008 from the Longitudinal Health Insurance Database (LHID). The LHID was a part of the National Health Insurance Research Databases (NHIRD). This database was established by the Taiwan National Health Insurance Administration, Ministry of Health and Welfare. The quality and accuracy of this database has been reported previously [16-18]. There were one million beneficiaries randomly sampled from the year 2000 Registry for Beneficiaries. All Taiwanese residents were obligated to join this program.

HP-infected male patients were identified as those who had a diagnosis of peptic ulcer upon admission and who had received HP eradication therapy within 1 year after peptic ulcer diagnosis [The International Classification of
Diseases, Ninth Revision, Clinical Modification (ICD-9CM) 531-533] from 1998 to 2008; these males were defined as the HP infection cohort. The date of HP infection diagnosis upon admission was defined as the index date. In addition, those patients aged $<20$ years or with a cancer history were excluded. Because there was a higher than 99\% population coverage rate in the Taiwan Bureau of National Health Insurance program, almost all HPinfected peptic ulcer patients received eradication therapy. Thus, it would be difficult to find an HP infection cohort without treatment in the current series. Therefore, for each HP-infected male patient, we selected four males for the comparison cohort who were without prior hospitalization for peptic ulcers or an HP eradication therapy history in the LHID; males in the comparison cohort were selected according to propensity score matching by age, index year, and comorbidity. Because there were no dates of HP infection diagnosis upon admission in the comparison cohort, we randomly assigned a date between 1998 and 2008 as the index date. As a result, there might be HP-infected male patients who visited an outpatient department only and therefore were not hospitalized in the comparison group. However, the exclusion criteria for the comparison cohort were the same as those for the HP infection cohort. A flow chart of the study subjects is depicted in Fig. 1.

This study was approved by the Research Ethics Committee at China Medical University and Hospital. The need for informed consent was waived for all participants [CMUH104-REC2-115]. To comply with research ethics and the Personal Information Protection Act, the identifications of all insured people were shuffled and replaced with surrogate numbers for completion of this research.

\section{H. pylori eradication therapy}

HP-infected peptic ulcer patients had received early HP eradication therapy in Taiwan; triple or quadruple therapy included a proton pump inhibitor or an $\mathrm{H} 2$ receptor blocker plus clarithromycin or metronidazole and amoxicillin or tetracycline, with or without bismuth. These drug combinations were prescribed within the same prescription order, and the duration of therapy was between 7 and 14 days [19].

\section{Baseline comorbidity and outcomes}

In this study, the following comorbidities were considered (ICD-9-CM): obesity (278), diabetes (250), smoking-related disease (including smoking [305.1], asthma [493], COPD [490-496], ischemic heart disease [410-414], and stroke [430-438]), alcohol-related illness (including alcoholic psychoses [ICD-9-CM code 291], alcohol dependence syndrome [ICD-9-CM code 303], alcohol abuse [ICD-9-CM code 305], alcoholic fatty liver [ICD-9-CM code 571.0], acute alcoholic hepatitis [ICD- 


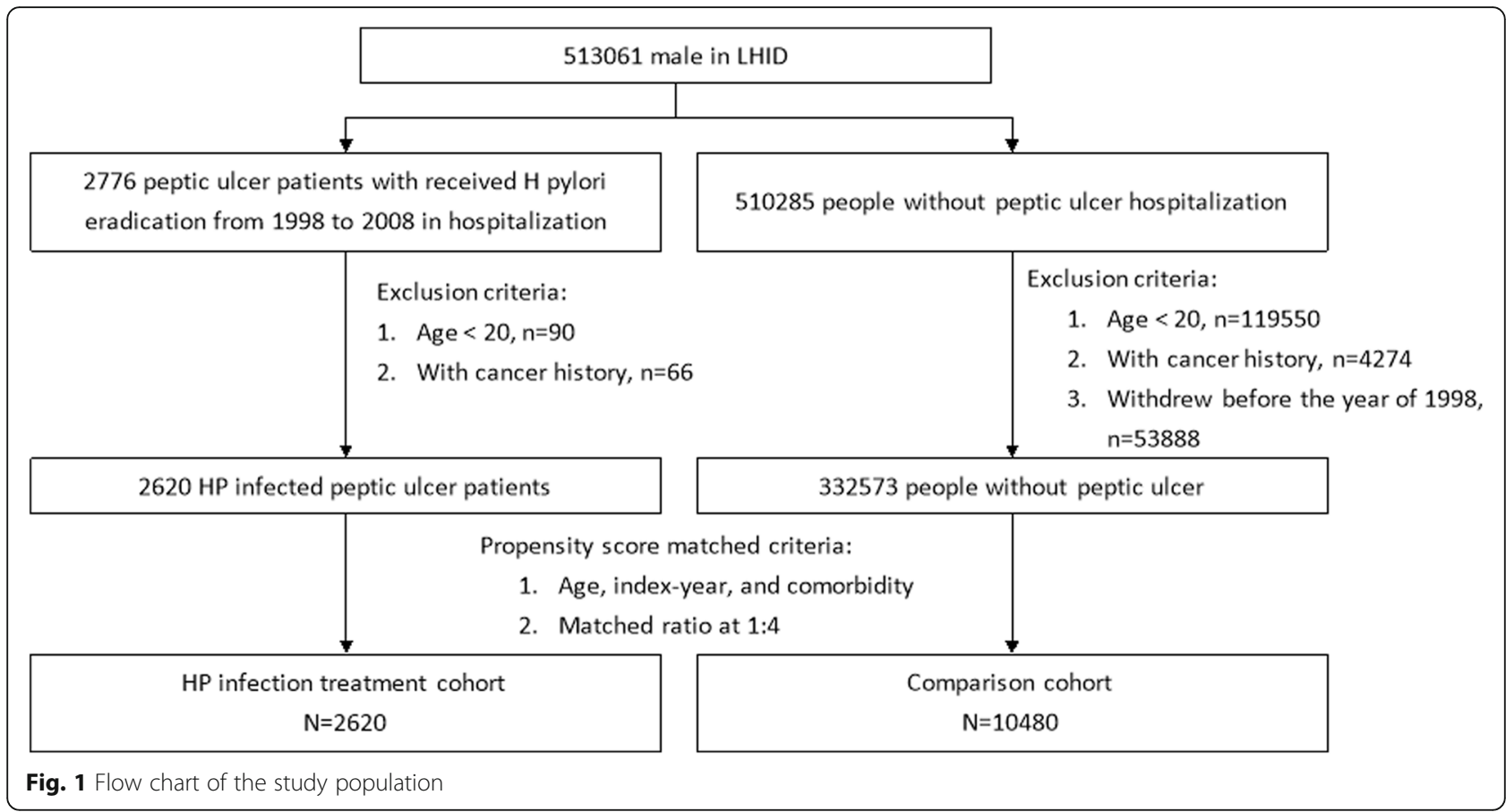

9-CM code 571.1], alcoholic cirrhosis [ICD-9-CM code 571.2], alcoholic liver damage [ICD-9-CM code 571.3]), prostatitis (601), BPH (600.0) and sexually transmitted disease $(054.1,091,096,098,099.5)$.

We considered these comorbidities because there is an increased risk of cancer associated with diabetes [20], alcohol $[21,22]$ and smoking [23, 24]. Moreover, prostatitis, BPH, and sexually transmitted diseases might play roles in the development of prostate cancer $[25,26]$. Therefore, we evaluated these comorbidities in the comparison and HP infection cohorts. These confounders were defined before the index date.

\section{Diagnosis of prostate cancer}

In addition to the ICD-9-CM system, cancer patients were precisely diagnosed by specialists based on pathology and clinical reports; then, they were entered into a registry system of "catastrophic illness patients" in Taiwan. Thus, we identified prostate cancer patients precisely from this "catastrophic illness patients" registry. The "catastrophic illness patients" registry and the LHID were both parts of the NHIRD, and they can be linked to each other by the identification of insurance identification number. In addition, all study subjects were followed from the index date until the development of prostate cancer. Patients without the development of prostate cancer were followed until the date they withdrew from the program or until the end of 2013, whichever came first.

\section{Statistical analysis}

All statistical analyses were performed using SAS software Version 9.4 (SAS Institute Inc., Cary, NC, USA), and the significance level was set at $p<0.05$; all tests were two-tailed. The number and percentage are presented for categorical variables such as age group (20$49,50-64$ and $65+$ years) and baseline comorbidities. The average age is presented as the mean and standard deviation. The difference in age and comorbidity was tested by counting standardized differences between the HP infection and comparison cohorts. The distribution was considered significant between cohorts when the standardized difference was larger than 0.1 .

The incidence of prostate cancer was defined as the sum of prostate cancer cases divided by the sum of follow-up years (person-years) in the HP infection treatment and comparison cohorts. Person-years were calculated from the index date until the end point occurred for each study subject. The association between the risk of prostate cancer and the evaluated risk factors was assessed by Cox proportional hazard regression after adjusting for matched pairs. The age- and comorbidity-stratified analyses were also estimated in the HP infection treatment and comparison cohorts using the Cox model as a sensitive test. The cumulative incidence of prostate cancer was plotted using Kaplan-Meier analysis, and the difference between the HP infection treatment and comparison cohorts was assessed with a log-rank test.

\section{Results}

A total of $2620 \mathrm{HP}$ infection treatment patients and 10, 480 matched comparisons were selected in this retrospective cohort study (Fig. 1). In the HP infection cohort, the mean age was $54.9 \pm 16.5$ years (Table 1 ). There 
Table 1 Distribution of age and comorbidity in the HP infection and comparison cohorts after propensity score matching

\begin{tabular}{|c|c|c|c|c|c|}
\hline \multirow[t]{2}{*}{ Variable } & \multicolumn{2}{|c|}{$\begin{array}{l}\text { HP infection treatment } \\
N=2620\end{array}$} & \multicolumn{2}{|c|}{$\begin{array}{l}\text { Comparison } \\
N=10,480\end{array}$} & \multirow[t]{2}{*}{$\begin{array}{l}\text { Standardized } \\
\text { differences }\end{array}$} \\
\hline & n & $\%$ & $n$ & $\%$ & \\
\hline \multicolumn{6}{|l|}{ Age, years } \\
\hline $20-49$ & 1063 & 40.6 & 4386 & 41.9 & 0.026 \\
\hline $50-64$ & 734 & 28.0 & 2731 & 26.1 & 0.044 \\
\hline $65+$ & 823 & 31.4 & 3363 & 32.1 & 0.015 \\
\hline Mean (SD) & 54.9 & $(16.5)$ & 54.6 & $(17.7)$ & 0.020 \\
\hline \multicolumn{6}{|l|}{ Comorbidity } \\
\hline Diabetes & 532 & 20.3 & 2159 & 20.6 & 0.007 \\
\hline Alcohol-related illness & 162 & 6.18 & 607 & 5.79 & 0.016 \\
\hline Smoking-related disease & 1238 & 47.3 & 5469 & 52.2 & 0.099 \\
\hline Prostatitis & 37 & 1.41 & 235 & 2.24 & 0.062 \\
\hline $\mathrm{BPH}$ & 102 & 3.89 & 525 & 5.1 & 0.054 \\
\hline Sex transmitted disease & 9 & 0.23 & 40 & 0.38 & 0.028 \\
\hline
\end{tabular}

SD Standard deviation

were no significant differences in comorbidity between the two cohorts. In the HP infection cohort, the three most common comorbidities were hypertension (47.3\%), diabetes (20.3\%), and alcohol-related illness (6.18\%). During the follow-up years, there were 36 patients in the HP infection cohort and 117 patients in the comparison cohort who developed prostate cancer; the incidence rates were 1.52 and 1.21 per 1000 person-years, respectively (Fig. 2). The HP infection cohort had a 1.26-fold increased prostate cancer risk compared with the comparison cohort in the Cox models after adjusting for matched pairs (95\% CI $=0.87-1.84$, Fig. 2$)$. The age- and comorbidity- risk of prostate cancer risk in the HP infection cohort was compared with that in the comparison cohort according to the Cox model. Regardless of age and comorbidity, there were no significant differences in subsequent prostate cancer development between the HP infection treatment and comparison cohorts (Fig. 2). However, after a 14-year follow-up, the cumulative incidence in the HP infection cohort was slightly higher than that in the comparison cohort $(2.43 \%$ vs. $2.24 \%)$ but this difference did not achieve statistical significance (log-rank test, $p=0.24$, Fig. 3).

\section{Discussion}

There is interest in HP infection and extragastric diseases. The effects of HP on idiopathic thrombocytopenic purpura, sideropenic anemia, and vitamin B12 deficiency have been well established [27], supporting the notion that some microorganisms can interfere with different biologic processes and cause diseases even remote from the primary infection sites [28].

A hypothetical model for HP infection has been proposed for prostate and bladder diseases [13]. Other studies have demonstrated an association between HP infection and urological diseases [14, 15], and intravesical vaccination against HP infection in chronic cystitis may confer protection against bladder lymphoma [29]. In addition, mucosa-associated lymphoid tissue lymphoma of the urinary bladder disappeared after $H$. pylori eradication therapy [30]. Furthermore, a recent study demonstrated the first molecular evidence of the presence of $H$. pylori DNA in prostatic tissue of patients with $\mathrm{BPH}$ and prostate cancer. However, this study was not able to show an association between $H$. pylori infection and prostate cancer due to the limited number of cases [15].

Inflammation may play an important role in the formation of cancer [31, 32], whereas ameliorating inflammation status might reduce the risk of cancer [33]. In addition, evidence has demonstrated an association between inflammation and prostate cancer [34], and HP infection was reported to be associated with chronic prostatitis [35]. In contrast, intriguing studies have demonstrated an inverse relationship between HP infection and gastric cardia cancer [11, 12]. This inconsistency may be explained by the advancement in hygiene and widespread antibiotic use and is supported by the corresponding decrease in HP infection [36].

There were no significant risks of subsequent prostate cancer in HP-infected peptic ulcer patients who received HP eradication therapy (Fig. 2); additionally, there were no differences in the cumulative incidence of prostate cancer between the comparison cohort and peptic ulcer patients who received HP eradication therapy (log-rank test, $p=0.24$, Fig. 3). There may have been HP-infected male patients who visited an outpatient department only (and therefore were not hospitalized) in the comparison group. The impact on prostate cancer risk in HP 


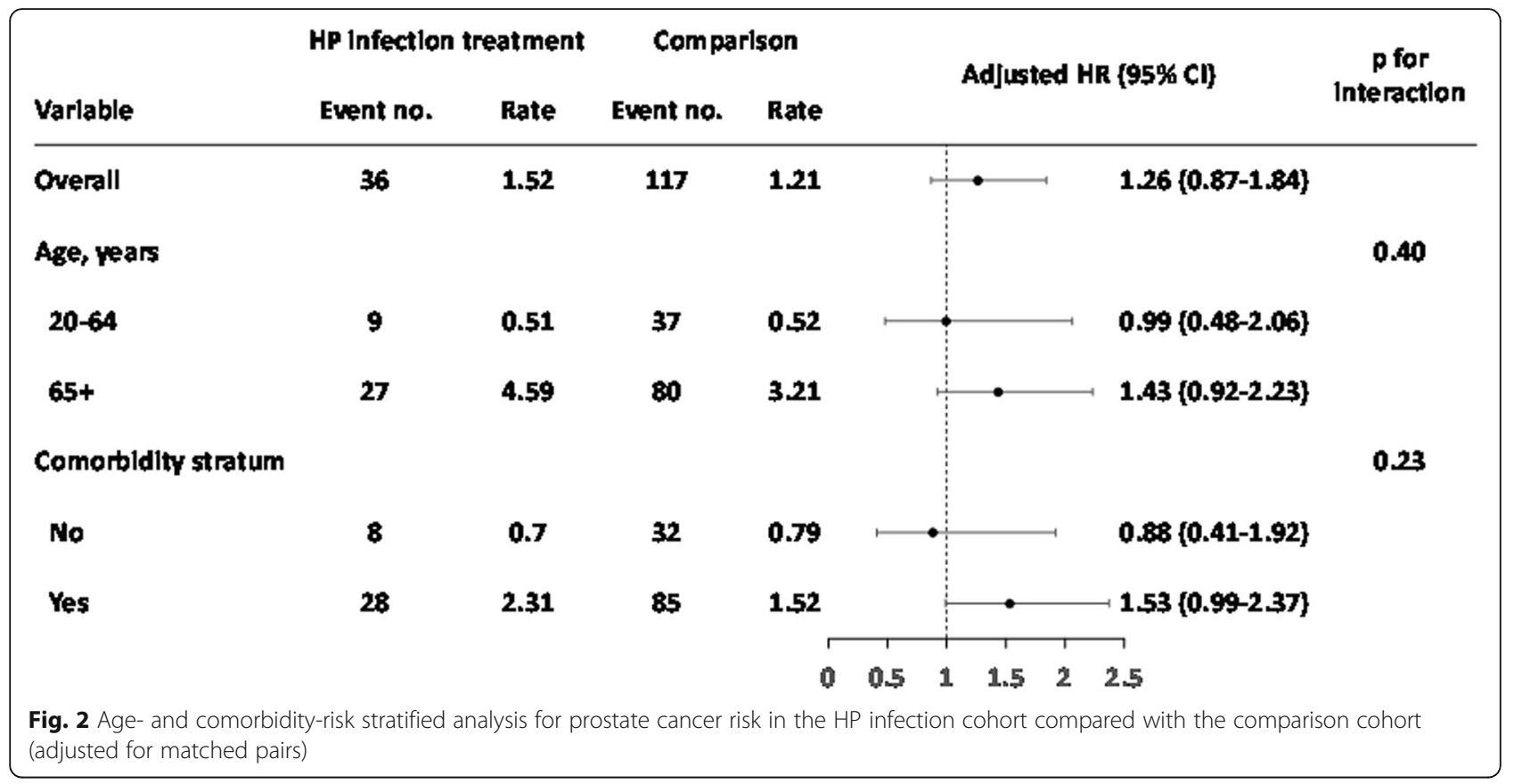

infection patients would not be overestimated under this condition.

In Taiwan, there was a higher than 99\% population coverage rate in the Taiwan Bureau of National Health Insurance program, and almost all HP-infected peptic ulcer patients received eradication therapy. The current nonsignificant results might be partly explained by a prompt HP eradication policy in HP-infected peptic ulcer patients within 1 year, which results in the suppression of HP infection-induced prostate inflammation. However, further studies are warranted to investigate the association of untreated HP infection and subsequent prostate cancer.

Little is known about the time period between gastrointestinal HP infection and prostate cancer development. In this study, the time period from the index date to an

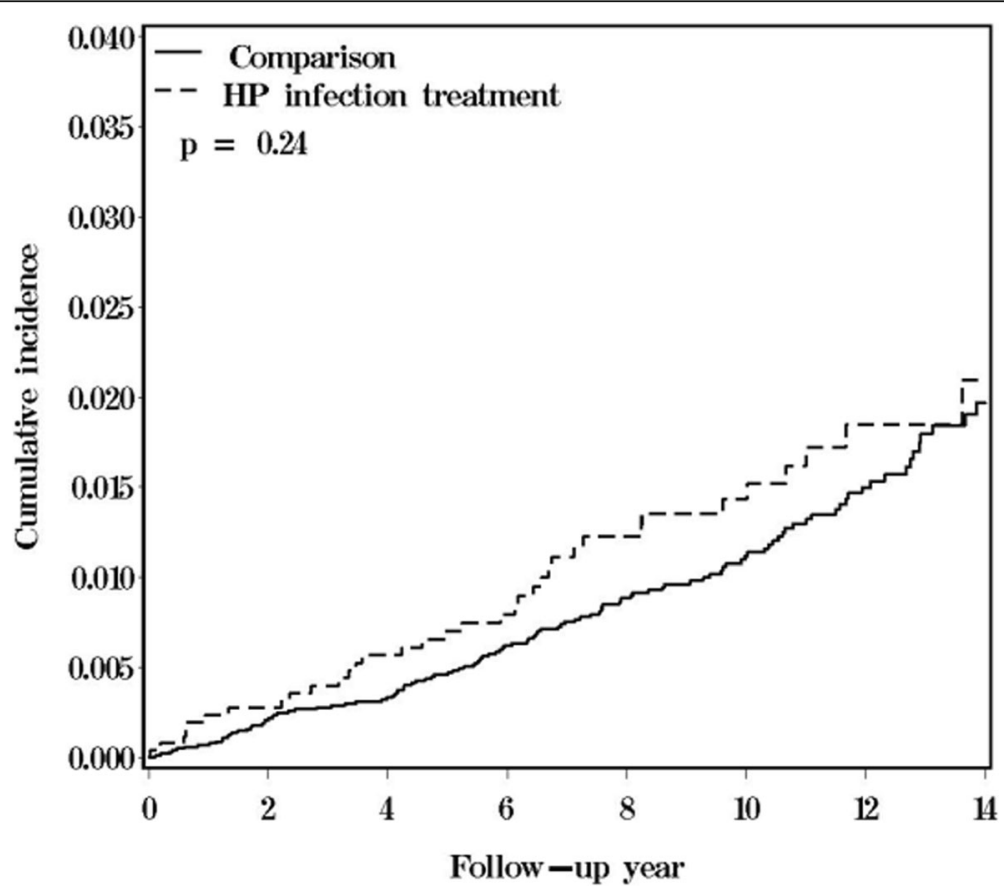

Fig. 3 Comparison of cumulative incidence of prostate cancer between the HP infection cohort and comparison cohort 
established prostate cancer diagnosis was $5.57 \pm 3.84$ and $6.39 \pm 3.88$ years in the HP infection treatment and comparison cohorts, respectively ( $p=0.27$ data not shown). This result demonstrated no differences in the timing of prostate cancer development between patients with and without HP infection treatment. One hypothesis is that the impacts of gastrointestinal HP infection might be diminished after eradication treatment.

There is a close association between aging and cancer $[37,38]$. Age is positively associated with the risk of prostate cancer [39]. In addition, the chance of prostate cancer increases rapidly after age 50 , and approximately $60 \%$ of prostate cancers occur in men older than 65 [40]. Although not significant in this study, older patients $(>65$ years old) had a higher incidence of prostate cancer development (Fig. 2), which is consistent with previous reports.

HP infection has been associated with lymphoma of the bladder [30, 41, 42], whereas the most common type of prostate cancer is adenocarcinoma. In this study, these two types of prostate cancer could not be distinguished because of database limitations. However, the associated impact might be minimal because the number of prostate cancers due to lymphoma is very low.

Body mass index (BMI) is a good index to compare comorbidities for prostate cancer [43, 44]. Because there was a lack of exact BMI values in our database, BMI was unable to be considered as a comorbidity for prostate cancer in this study.

There have been studies that demonstrated the impact of gastrointestinal HP infection on the subsequent risk of prostate cancer [15], and the association of HP infection with both chronic prostatitis [35] and an increased risk of prostate inflammation [45]. To our knowledge, there have been no similar epidemiological studies focusing on the impact of eradicated HP infection and subsequent risk of prostate cancer. In this study, no significant associations were noted between HP-infected peptic ulcer patients and the subsequent risk of prostate cancer. HP infection was reported to be associated with chronic prostatitis [35] and might increase the risk of prostate inflammation [45]. Further investigations are needed to elucidate whether our result can be attributed to a prompt HP eradication policy. In addition, further studies might be focused on whether suppression of HP infection has a benefit in reducing HP-induced prostate inflammation or prostate cancer risk.

\section{Limitations of the study}

With reliable diagnosis and a high follow-up rate, our study was strengthened by available data in a large population for longitudinal assessment. However, there were certain limitations. First, lifestyle variables such as drinking, smoking, dietary habits, socioeconomic status, and genetic information were not available for the adjustment of prostate cancer risk estimates. Second, all data used were anonymous, and there was a lack of relevant clinical variables, such as pathology findings, imaging results and laboratory data. Third, the lack of the exact duration between HP infection and HP eradication therapy may have partially neutralized the study findings. Fourth, patients with minor peptic ulcer symptoms may have sought over-the-counter remedies. Therefore, peptic ulcer patients seek for medical services might be a biased group. Additionally, HP infection patients were diagnosed according to codes and those who underwent eradication therapy rather than precise tests. Fifth, there was a lack of data on prostate cancer screening, staging, and status, as well as an established result of HP eradication therapy. Finally, biases related to the retrospective nature of the study and the limited number of patients should be noted.

\section{Conclusion}

In this long-term cohort study, our findings showed no significant association between HP-infected peptic ulcers and the subsequent risk of prostate cancer.

Further studies are warranted to investigate whether this is attributable to the HP eradication policy.

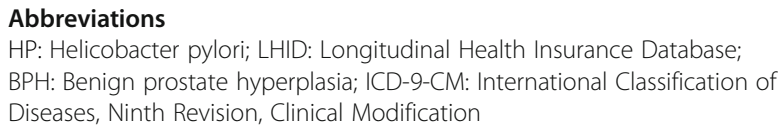

\section{Acknowledgements}

Not applicable.

Guarantor of the article: Shih-Chi Wu, MD, PhD.

\section{Authors' contributions}

FCW conceived and designed the study as well as wrote the initial draft of the manuscript; $\mathrm{CCH}$ participated in study design and conception; $\mathrm{MCH}$ performed data analysis and interpretation and was involved in writing the initial draft of the manuscript. WSC designed the study, performed data analysis and interpretation and was involved in manuscript drafting and revision. All authors have read and approved the manuscript.

\section{Funding}

This study is supported in part by Ministry of Health and Welfare, Taiwan (109-TDU-B-212-114004), MOST Clinical Trial Consortium for Stroke (MOST 108-2321-B-039-003)

The funders had no role in study design, data collection and analysis, decision to publish, or preparation of the manuscript.

\section{Availability of data and materials}

This study used inpatient claims data from the Taiwan National Health Insurance Research Database (NHIRD). This database contains detailed medical histories of the hospitalized enrollees in Taiwan. Based on the guideline of Taiwan Ministry of Health and Welfare (TMHW), only citizens of the Taiwan are eligible to apply the NHIRD for research projects (https:// nhird.nhri.org.tw/en/Data_Protection.html).

The database we applied is only limited to our research purpose. All applicants must follow the Computer-Processed Personal Data Protection Law and related regulations of National Health Insurance Administration and NHRI (http://www.winklerpartners.com/?p=987).

The ownership of NHIRD is belong to TMHW and the right to use is belong to the researchers. However, other researchers are able to request data access following the regulations of TMHW. 


\section{Ethics approval and consent to participate}

This study was approved by the Research Ethics Committee at China Medical University and Hospital. The need for informed consent was waived from all participants [CMUH104-REC2-115 (CR-3)]. To comply with research ethics and the Personal Information Protection Act, the identifications of all insured people were shuffled and replaced with surrogate numbers for research.

\section{Consent for publication}

Not applicable.

\section{Competing interests}

The authors have declared that no competing interests exist.

\section{Author details}

${ }^{1}$ Division of Urology, Department of Surgery, Chi Mei Medical Center, Tainan, Taiwan. ${ }^{2}$ Management Office for Health Data, China Medical University Hospital, Taichung, Taiwan. ${ }^{3}$ School of medicine, China Medical University, Taichung, Taiwan. ${ }^{4}$ Trauma and Emergency Center, China Medical University Hospital, No. 2, Yuh-Der Road, Taichung 404, Taiwan.

Received: 27 May 2020 Accepted: 24 August 2020

Published online: 31 August 2020

\section{References}

1. Kuipers EJ, Thiis JC, Festen HP. The prevalence of helicobacter pylori in peptic ulcer disease. Aliment Pharmacol Ther. 1995;9(Suppl 2):59-69.

2. O'Connor A, Gisbert JP, O'Morain C, et al. Treatment of helicobacter pylori infection 2015. Helicobacter. 2015;20(Suppl 1):54-61.

3. Treiber G, Wittig J, Ammon S, Walker S, van Doorn L, Klotz U. Clinical outcome and influencing factors of a new short-term quadruple therapy for helicobacter pylori eradication: a randomized controlled trial (MACLOR study). Arch Intern Med. 2002;162:153-60.

4. Atherton JC. The pathogenesis of helicobacter pylori-induced gastroduodenal diseases. Annu Rev Pathol. 2006;1:63-96.

5. Kusters JG, van Vliet AH, Kuipers EJ. Pathogenesis of helicobacter pylori infection. Clin Microbiol Rev. 2006;19(3):449-90.

6. Guo Y, Liu W, Wu J. Helicobacter pylori infection and pancreatic cancer risk: A meta-analysis. J Cancer Res Ther. 2016;12(Supplement):C229-32.

7. Zhao Y, Wang X, Wang Y. Helicobacter pylori infection and colorectal carcinoma risk: a meta-analysis. J Can Res Ther. 2016;12:15-8.

8. Zhang Y, Hoffmeister M, Weck MN, et al. Helicobacter pylori infection and colorectal cancer risk: evidence from a large population-based case-control study in Germany. Am J Epidemiol. 2012;175(5):441-50.

9. Xie FJ, Zhang YP, Zheng QQ. Helicobacter pylori infection and esophageal cancer risk: an updated meta-analysis. World J Gastroenterol. 2013;19(36): 6098-107.

10. Islami F, Kamangar F. Helicobacter pylori and esophageal cancer risk: a meta-analysis. Cancer Prev Res (Phila). 2008;1(5):329-38.

11. Kamangar F, Dawsey SM, Blaser MJ, et al. Opposing risks of gastric cardia and noncardia gastric adenocarcinomas associated with helicobacter pylori seropositivity. J Natl Cancer Inst. 2006;98(20):1445-52.

12. Ye W, Held M, Lagergren J, et al. Helicobacter pylori infection and gastric atrophy: Risk of adenocarcinoma and squamous-cell carcinoma of the esophagus and adenocarcinoma of the gastric cardia. J Natl Cancer Institute. 2004;96(5):388-96.

13. Al-Marhoon MS. Is there a role for Helicobacter pylori infection in urological diseases? Urol J. 2008;5(3):139-43.

14. Verit $\mathrm{A}$, Yüksel ÖH, Kivrak M, et al. Are helicobacter pylori and benign prostatic hyperplasia related, and if so, how? Urol J. 2015 Sep 4;12(4):2271-5.

15. Al-Marhoon MS, Ouhtit A, Al-Abri AO, et al. Molecular evidence of helicobacter pylori infection in prostate tumors. Curr Urol. 2015 Sep;8(3):138-43.

16. Cheng $\mathrm{CL}$, Kao YH, Lin SJ, Lee $\mathrm{CH}$, Lai ML. Validation of the National Health Insurance Research Database with ischemic stroke cases in Taiwan. Pharmacoepidemiol Drug Saf. 2011;20(3):236-42.

17. Cheng CL, Chien HC, Lee CH, Lin SJ, Yang YH. Validity of in-hospital mortality data among patients with acute myocardial infarction or stroke in National Health Insurance Research Database in Taiwan. Int J Cardiol. 2015; 201:96-101.

18. Kao WH, Hong JH, See LC, Yu HP, Hsu JT, Chou IJ, Chou WC, Chiou MJ, Wang CC, Kuo CF. Validity of cancer diagnosis in the National Health
Insurance database compared with the linked National Cancer Registry in Taiwan. Pharmacoepidemiol Drug Saf. 2018;27(10):1060-6.

19. Wu CY, Wu MS, Kuo KN, Wang CB, Chen YJ, Lin JT. Effective reduction of gastric cancer risk with regular use of nonsteroidal anti-inflammatory drugs in helicobacter pylori-infected patients. J Clin Oncol. 2010;28(18):2952-7.

20. Giovannucci E, Harlan DM, Archer MC, et al. Diabetes and cancer: a consensus report. Diabetes Care. 2010;33(7):1674-85.

21. Boffetta P, Hashibe M. Alcohol and cancer. Lancet Oncol. 2006;7:149-56. https://doi.org/10.1016/S1470-2045(06)70577-0.

22. Meadows GG, Zhang $\mathrm{H}$. Effects of alcohol on tumor growth, metastasis, immune response, and host survival. Alcohol Res. 2015;37:311-22.

23. Zeegers MP, Tan FE, Dorant E, et al. The impact of characteristics of cigarette smoking on urinary tract cancer risk: a meta-analysis of epidemiologic studies. were associated with the development of cancer. Cancer. 2000;89(3):630-9.

24. Pesch B, Kendzia B, Gustavsson P, et al. Cigarette smoking and lung cancer-relative risk estimates for the major histological types from a pooled analysis of case-control studies. Int J Cancer. 2011;131(5):1210-9.

25. Cheng I, Witte JS, Jacobsen SJ, et al. Prostatitis, sexually transmitted diseases, and prostate cancer: the Califomia Men's Health Study. PLoS One. 2010,5(1):e8736 Published 2010 Jan 15.

26. Caini S, Gandini S, Dudas M, et al. Sexually transmitted infections and prostate cancer risk: a systematic review and meta-analysis. Cancer Epidemiol. 2014;38(4):329-38

27. Goni E, Franceschi F. Helicobacter pylori and extragastric diseases. Helicobacter. 2016;21(Suppl 1):45-8.

28. Ražuka-Ebela D, Giupponi B, Franceschi F. Helicobacter pylori and extragastric diseases. Helicobacter. 2018:23(Suppl 1):e12520.

29. Pastuszka A, Slusarczyk K, Koszutski T, Kudela G, Kawalski H. Intravesical vaccination against helicobacter pylori in patients with chronic cystitis may confer protection against MALT-type lymphoma of the bladder. Med Hypotheses. 2007;69:1160-1.

30. van den Bosch J, Kropman RF, Blok P, Wijermans PW. Disappearance of a mucosa-associated lymphoid tissue (MALT) lymphoma of the urinary bladder after treatment for helicobacter pylori. Eur J Haematol. 2002;68:187-8.

31. Bhatelia $K$, Singh $K$, Singh R. TLRs: linking inflammation and breast cancer. Cell Signal. 2014;26(11):2350-7.

32. Balkwill F, Mantovani A. Inflammation and cancer: back to Virchow? Lancet. 2001;357:539-45.

33. Todoric J, Antonucci L, Karin M. Targeting inflammation in Cancer prevention and therapy. Cancer Prev Res (Phila). 2016;9(12):895-905.

34. Sfanos KS, De Marzo AM. Prostate cancer and inflammation: the evidence. Histopathology. 2012;60(1):199-215.

35. Abdollahi A, Etemadian M, Shoar S, et al. Is Helicobacter pylori Infection a Risk Factor for Prostatitis? A Case-Control Study in a Referring Tertiary Care Center. Iran J Pathol. 2016;11(4):323-7.

36. Kamangar F, Qiao YL, Blaser MJ, et al. Helicobacter pylori and oesophageal and gastric cancers in a prospective study in China. Br J Cancer. 2007;96(1):172-6.

37. Toren Finkel T, Serrano M, Blasco MA. The common biology of cancer and ageing. Nature. 2007:448:767-74.

38. Lichtman SM, et al. Geriatric oncology: a field coming of age. J Clin Oncol. 2007:25:1821-3.

39. Pourmand G, Salem S, Mehrsai A, et al. The risk factors of prostate cancer: a multicentric case-control study in Iran. Asian Pac J Cancer Prev. 2007;8(3):422-8.

40. American Cancer Society. Facts \& Figures 2015. Atlanta: American Cancer Society; 2015

41. Montalban C, Santon A, Boixeda D, et al. Treatment of low grade gastric mucosa-associated lymphoid tissue lymphoma in stage I with helicobacter pylori eradication. Long-term results after sequential histologic and molecular follow-up. Haematologica. 2001;86(6):609-17.

42. Fujimura M, Chin K, Sekita N, et al. Regression of mucosa-associated lymphoid tissue lymphoma of the bladder after antibiotic therapy: a case report (in Japanese). Hinyokika Kiyo. 2008;54:783-6.

43. Lee A, Chia SJ. Prostate cancer detection: The impact of obesity on Asian men. Urol Oncol. 2015;33(6):266.e17-266.e2.66E22. https://doi.org/10.1016/j.urolonc.2015.03.011.

44. Wang K, Chen X, Gerke TA, Bird VY, Ghayee HK, Prosperi M. BMI trajectories and risk of overall and grade-specific prostate cancer: an observational cohort study among men seen for prostatic conditions. Cancer Med. 2018;7(10):5272-80.

45. Porter $\mathrm{CM}$, Shrestha E, Peiffer $\mathrm{LB}$, et al. The microbiome in prostate inflammation and prostate cancer. Prostate Cancer Prostatic Dis. 2018;21(3):345-54.

\section{Publisher's Note}

Springer Nature remains neutral with regard to jurisdictional claims in published maps and institutional affiliations. 